\title{
Progression of first degree heart block to high-grade second degree block during spinal anaesthesia
}

\begin{abstract}
A case is presented in which a patient with pre-existing first degree heart block developed high-grade second degree heart block during spinal anaesthesia. Progression of the block was associated with blockade of cardiac sympathetic neurons induced by spinal anaesthesia. This suggests that patients with pre-existing heart block may be at increased risk for development of higher grade block during spinal anaesthesia.
\end{abstract}

Le cas présenté est celui d'un patient porteur d'un bloc cardiaque du premier degré à l'évaluation préopératoire, et qui a développé un bloc du deuxième degré de haut niveau lors d'une anesthésie sous-arachnoïdienne. La progression du bloc était associée au blocage des neurones sympathiques cardiaques induit par l'anesthésie sous-arachnoïdienne. Ceci suggère que les patients avec un bloc cardiaque à l'évaluation préopératoire peuvent être à risque de développer un bloc de haut niveau pendant une anesthésie sous-arachnoìdienne.

Blockade of cardiac sympathetic neurons by high spinal anaesthesia has been associated with bradycardia, sinus arrest and third degree heart block. ${ }^{1,2}$ These effects are thought to result from loss of sympathetic tone and emergence of unopposed parasympathetic influences on the sinus node and the atrioventricular (AV) node.

However, previous reports of arrythmias associated with

\section{Key words}

ANAESTHETIC TECHNIQUES: spinal;

HEART: arrhythmia;

PARASYMPATHETIC NERVOUS SYSTEM;

SYMPATHETIC NERVOUS SYSTEM.

From the Department of Anesthesiology, RN-10, University of Washington, Seattle, Washington, 98195.

Address correspondence to: Dr. C.M. Bernards, Department of Anesthesiology, RN-10, University of Washington, Seattle, Washington, 98195.

Accepted for publication 7 th October, 1991.

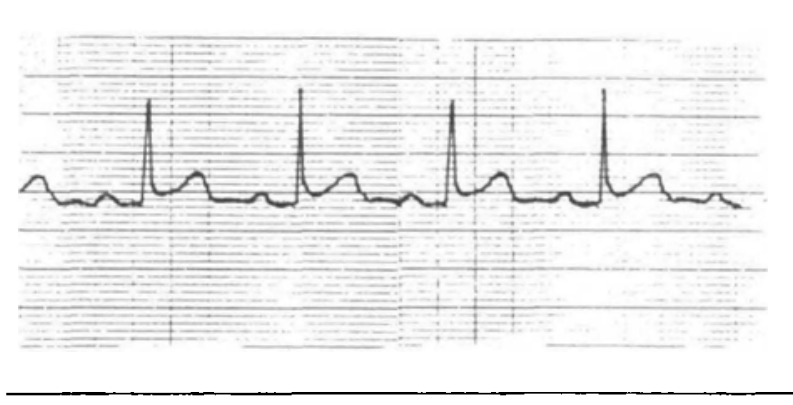

FIGURE I Preoperative lead II rhythm strip demonstrating preexisting first degree AV block (PR interval $=0.24 \mathrm{msec}$ ) and a normal QRS duration (0.08 msec).

spinal anaesthesia have not identified risk factors which might predict sinus or AV node dysfunction during high spinal anaesthesia. We present the first report of a case in which pre-existing first degree AV block progressed to high-grade second degree heart block following spinal anaesthesia-induced blockade of cardiac sympathetic neurons. This case suggests that first degree AV block may be a risk factor for higher grade AV block during high spinal anaesthesia.

\section{Case report}

A 32-yr-old, $65 \mathrm{~kg}$ woman was brought to the operating room approximately four hours after sustaining lacerations of the knee joint and face in an automobile accident. She was scheduled for irrigation, debridement and wound closure. Her medical history and physical examination were unremarkable except that she was six weeks pregnant. Specifically, she denied chest injury, acute infection, rheumatic fever, myocardial infarction, syncopal episodes, and palpitations. A preoperative lead II rhythm strip revealed first degree AV block (PR interval $0.24 \mathrm{msec}$ ) and a normal QRS duration $(0.08 \mathrm{msec})$ (Figure 1$)$. The complete blood count and electrolyte concentrations were within the normal range. Blood alcohol concentration was $0 \mathrm{mg} \cdot \mathrm{dl}^{-1}$. She was taking no medications, denied using illicit drugs and had no known drug allergies. She had 


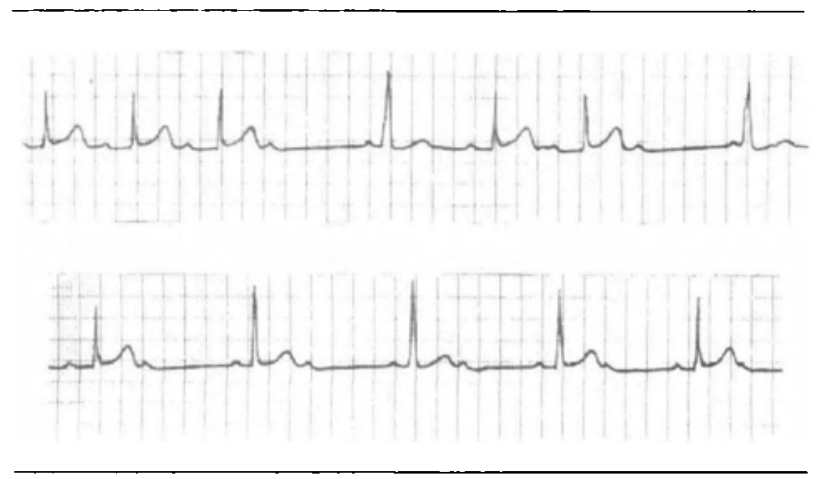

FIGURE 2 Top rhythm strip (lead II) shows initial presentation of second degree type 1 (Wenckebach) AV block with a 4:3 conduction ratio. Bottom strip shows high-grade second degree block with a 2:1 conduction ratio which occurred within 15 seconds after the $4: 3$ block developed.

received tetanus toxoid, cefazolin $(1 \mathrm{~g})$ and thiamine (10 $\mathrm{mg}$ ) in the emergency room before transfer to the operating room.

An 18-gauge intravenous catheter was placed and 600 $\mathrm{ml}$ Ringer's lactate and $4 \mathrm{mg}$ morphine were given $i v$. The blood pressure was $118 / 58$, and heart rate was 84 beats per minute (sinus rhythm). She was placed in the left lateral decubitus position and $60 \mathrm{mg} 5 \%$ lidocaine in $10 \%$ dextrose with $200 \mu \mathrm{g}$ epinephrine was injected into the subarachnoid space at the $\mathrm{L}_{4-5}$ level. She remained in the left lateral decubitus position for two minutes and was then turned supine. Seven minutes later sensory block was evaluated by pin prick and found to be at the level of $T_{4}$ on the right and $T_{3}$ on the left. Over the next several minutes she developed Type I second degree heart block (Wenckebach) with a 4:3 conduction ratio which progressed within $15 \mathrm{sec}$ to high-grade second degree block with a 2:1 conduction ratio (Figure 2). Blood pressure decreased to $90 / 48$. Atropine $(0.6 \mathrm{mg})$ was administered iv and the second degree heart block converted to a junctional tachycardia (110 bpm) which changed over the next one to two minutes to sinus tachycardia (125 bpm) with resolution of her first degree AV block (PR interval $0.2 \mathrm{msec}$ ) (Figure 3).

The patient experienced no untoward effects. She received bilateral supraorbital nerve blocks for closure of her facial lacerations. The remainder of the intraoperative and postoperative course was uneventful. A 12-lead ECG before discharge demonstrated return of first degree $A V$ block but no other abnormalities. She was discharged two days after surgery.

\section{Discussion}

There are multiple causes of type I second degree AV block including myocarditis, acute infection, inferior myocardial infarction, uraemia and digitalis excess. ${ }^{3}$

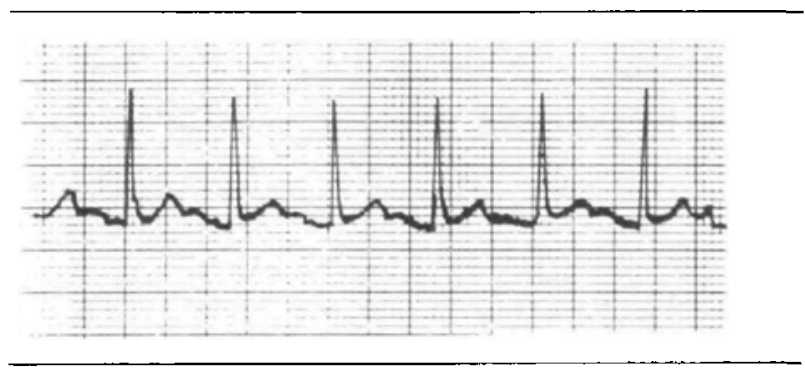

FIGURE 3 Sinus tachycardia which developed after treatment of 2:1 AV block with atropine. Of note is the retum to $1: 1 \mathrm{AV}$ conduction and the normalization of the PR interval $(0.2 \mathrm{msec})$.

However, it seems likely that the sudden onset of second degree AV block in this patient resulted from high spinal anaesthesia. With a sensory block at $T_{3} / T_{4}$, it would be expected that most, if not all, cardiac sympathetic fibres had been blocked. ${ }^{4,5}$ It is the loss of sympathetic innervation which may have caused the rhythm to progress from first degree AV block to second degree block.

The AV node is divisible into three electrophysiologically distinct regions, (1) atrial-nodal, (2) nodal and (3) nodal-His bundle. Conduction through the nodal region is influenced equally but in opposite directions by the sympathetic and parasympathetic nervous systems. ${ }^{6} \mathrm{Sym}-$ pathetic innervation of $A V$ nodal cells enhances AV conduction by increasing inward calcium currents and decreasing outward potassium currents; parasympathetic innervation slows $\mathrm{AV}$ conduction time by decreasing inward calcium currents and increasing outward potassium currents. ${ }^{7}$ Both first degree AV block and Type I second degree block occur predominantly in the autonomically influenced nodal region of the AV node. ${ }^{8,9}$ Neither sympathetic nor parasympathetic stimulation alters conduction through the atrial-nodal or nodal-His regions. ${ }^{10}$

There was no obvious pathology to explain this patient's pre-existing first degree AV block, although first degree $\mathrm{AV}$ block can exist in young persons in the absence of organic heart disease. ${ }^{11}$ However, the presence of first degree AV block demonstrates impaired conduction through the AV node at baseline. The cardiac sympathectomy which accompanied the spinal block deprived the nodal tissues of the compensatory sympathetic stimulation which normally acts to enhance AV conduction. The result was unopposed parasympathetic stimulation which would be expected to delay AV conduction further and probably accounts for the progression from first degree AV block to second degree block. Further evidence for this mechanism is that parasympathetic blockade with atropine resulted in a return to 1:1 AV conduction and a normal PR interval.

Progression of heart block could have resulted from an absolute increase in cardiac parasympathetic tone as well. 
Baroreflex mediated increase in cardiac vagal tone resulting from decreased venous return has been demonstrated during lumbar epidural anesthesia. ${ }^{12}$ However, this patient received a volume load prior to the spinal block and showed no evidence of diminished venous return (e.g., hypotension) or enhanced vagal tone (e.g., decreased heart rate) before the onset of second degree heart block. Therefore, diminished sympathetic tone would seem the most likely explanation for the progression of heart block.

Given this patient's rapid progression from first degree AV block through Type I second degree block to high grade 2:1 block, it is reasonable to question whether the rhythm would have progressed to complete heart block: previous reports of third degree AV block resulting from high spinal anaesthesia are consistent with this possibility.

It is also important to question whether persons with other forms of preexisting heart block, such as Type II second degree block, bundle branch block or fascicular block, might similarly progress to higher grade blocks following spinal anaesthesia-induced cardiac sympathectomy. These blocks all occur below the level of the AV node either in the His bundle, the bundle branches or the fascicles. Conduction through these tissues is not influenced by the autonomic nervous system; therefore, loss of myocardial sympathetic tone would not be expected to worsen infranodal blocks.

\section{Conclusion}

This is the first reported case of high spinal anaesthesia resulting in progression of first degree heart block to highgrade second degree heart block. The electrophysiology of the AV node suggests that this may be a consequence of spinal anaesthesia-induced cardiac sympathetic blockade in persons with pre-existing AV block. It would seem prudent to be alert for any changes in AV conduction during high spinal anaesthesia in persons with preexisting first degree heart block. In addition, if this or similar patients are to receive conduction block (spinal, caudal or epidural) outside of the operating room (e.g., labour and delivery) then continuous ECG monitoring should be considered. In contrast, infranodal blocks (Type II second degree block, bundle branch blocks or fascicular blocks) would not be expected to progress to higher grade block as a consequence of high spinal anaesthesia.

\section{References}

1 Chester WL. Spinal anesthesia, complete heart block, and the precordial chest thump: an unusual complication and a unique resuscitation. Anesthesiology 1988; 69: 600-2.

2 Westone WL, Wong KC. Sinus bradycardia and asystole during spinal anesthesia. Anesthesiology 1974; 41: 87-9.

3 Chung EK. Principals of Cardiac Arrythmias. Baltimore: Williams and Wilkins, 1989, 295.
4 Greene NM. The area of differential block during spinal anesthesia with hyperbaric tetracaine. Anesthesiology 1958; 19: 45-50.

5 Chamberlain DP, Chamberlain BDL. Changes in skin temperature of the trunk and their relation to sympathetic blockade during spinal anesthesia. Anesthesiology 1986; 65: 139-43.

6 Prystowsky EN, Jackman WM, Rinkenberger RL, Heger $J J$, Zipes DP. Effect of autonomic blockade on ventricular refractoriness and atrioventricular nodal conduction in humans. Evidence supporting direct cholinergic action on ventricular muscle refractoriness. Circ Res 1981; 49: 511-8.

7 Irisawa H, Giles WR. Sinus and atrioventricular node cells: cellular electrophysiology. In: Zipes DP, Jaliffe J (Eds.). Cardiac Electrophysiology from Cell to Bedside. Philadelphia: WB Saunders, 1990: 95-102.

8 Chung EK. Principals of Cardiac Arrythmias. Baltimore: Williams and Wilkins, 1989; 281.

9 Watanabe Y, Dreifus $L S$. Atrioventricular block: basic concepts. In: Mandel WJ (Ed.). Cardiac Arrythmias: Their Mechanisms, Diagnosis and Management. Philadelphia: JB Lippincott, 1980: 406-36.

10 Corr PB, Yamada KA, Witkowski FX. Mechanisms controlling cardiac autonomic function and their relation to arrythmogenesis. In: Fozzard HA, Haber E, Jennings RB, Katz AM, Morgan HE (Eds.). The Heart and Cardiovascular System. New York: Raven Press, 1986: 1343-403.

11 Johnson RL, Averill KH, Lamb LE. Electrocardiographic findings in 67,375 asymptomatic subjects VII: atrioventricular block. Am J Cardiol 1960; 6: 153-77.

12 Baron JF, Decaux-Jacolot A, Edouard A, Berdeaux A, $K a m r a n S$. Influence of venous retum on baroreflex control of heart rate during lumbar epidural anesthesia in humans. Anesthesiology 1986; 64: 188-93. 